\title{
Experimental and Computational Investigation of Hybrid FRP Bonded-Reinforced Concrete Beams under Cyclic
}

\section{Loading}

\author{
Hasan Nikopour ${ }^{1}$, M. Nehdi ${ }^{2}$ and P. Broumand ${ }^{3}$ \\ 1. Department of Civil Engineering and Applied Mechanics, McGill University, Montreal, QC H3A 2K6, Canada \\ 2. Department of Civil and Environmental Engineering, The University of Western Ontario, London, Ontario N6A 5B9, Canada \\ 3. Department of Civil Engineering, Sharif University of Technology, Tehran, Iran
}

\begin{abstract}
Although several experimental and numerical studies have been carried out on the shear capacity of RC beams retrofitted by carbon or glass fibre-reinforced polymers, there has been little work on hybrid FRP sheet applications, particularly under cyclic loading. In the present research, five RC beams were constructed, and four of which were retrofitted using various schemes of FRP sheets. All beams were subjected to quasi-static cyclic loading in an attempt to represent the effect repetitive loading. The ultimate load, and deflection response at mid-span of the beams were measured and compared with predictions of a computational model based on finite element analysis. Experimental results demonstrated that hybrid applications of FRP sheets can improve the shear performance of retrofitted RC beams and increase the ultimate strain of the FRP sheets at failure. The results of the computational model were in reasonable agreement with the corresponding experimental results.
\end{abstract}

Key words: Beams, reinforced concrete, fibre-reinforced polymer, shear strength, finite element method.

\section{Introduction}

Innovative composite materials known as fibre-reinforced polymers (FRP) have shown great promise in the rehabilitation of ageing reinforced concrete (RC) structures. The rehabilitation of these structures is usually in the form of strengthening of structural members, repair of damaged structures, or retrofitting for seismic deficiencies. Composite materials have proven to be an excellent option as external reinforcement because of their high tensile strength, lightweight, resistance to corrosion, high durability, and ease of installation. Several experimental and analytical studies have been carried out on RC beams retrofitted with FRP sheets having long unidirectional fibres [1-6]. Computational

Corresponding author: Hasan Nikopour, PhD candidate, research fields: applied mechanics, structural engineering, and composite materials. hasan.nikopourdeilami@mail.mcgill.ca. modelling was also used by several researchers for linear and non-linear problems associated with retrofit of RC elements with external FRP [7-13].

The transverse behaviour of a external FRP reinforced element represents the weakest link in the load transfer capabilities of the composite and thus merits detailed attention [14]. Application of hybrid FRP can enhance the transverse properties. For instance, $\mathrm{Wu}$ et al. [15] carried out an experimental research on the application of hybrid FRP sheets as external confinement for concrete cylinders. They concluded that this reinforcement scheme can significantly enhance the strength and ductility, resulting in a large energy absorption capacity of specimens. Li et al. [16] conducted an experimental study on the reinforcement of concrete beam-column connections with hybrid FRP sheets. Their results show that retrofitting critical sections of concrete frames with FRP reinforcement can provide significant gains in strengthening and stiffening of such frames and 
improving their behaviour under different types of loading. Li et al. [17] later reported the results of an experimental study conducted on RC beams retrofitted in flexure using hybrid FRP sheets. It was indicated that hybrid sheets allow the transfer of stress in the hybrid composite between carbon fibres and glass fibres, and further improve ductility. Sakar et al. [18] reported results of an experimental research on the application of bidirectional CFRP sheets for retrofitting $\mathrm{RC}$ beams under cyclic loading. It was concluded that adding a horizontal ply in the $0^{\circ}$ direction has a considerable effect of increasing the shear capacity.

Little research was accessible in the open literature on the application of hybrid sheets of different FRP materials as external reinforcement for the shear rehabilitation of RC beams. To develop experimental data on the ultimate shear load capacity, deflection, crack pattern, mode of failure, and strain for RC beams retrofitted using hybrid FRP sheets as external reinforcement under quasi-static cyclic loading, five full-scale RC beams with different type of external reinforcement were constructed and tested in this study. All beam specimens were loaded to failure under quasi-static cyclic loading. To relate experimental results to theory, the finite-element technique was utilized.

\section{Experimental Program}

The experimental program was conducted in this research involved five tests on rectangular RC beams that were designed so that their ultimate shear capacity was reached before their flexural failure.

\subsection{Materials Properties}

A relatively low strength concrete (25 $\mathrm{MPa})$ was selected for casting the beam specimens in order to emphasize the need for retrofit. The mix design of the concrete used was as follows: cement $=375 \mathrm{~kg} / \mathrm{m}^{3}$, coarse aggregate (well graded, $28-\mathrm{mm}$ nominal maximum-size rounded gravel) $=1200 \mathrm{~kg} / \mathrm{m}^{3}$, fine aggregate (natural sand with an oven dry relative density of 2.64 and absorption of $0.7 \%)=600 \mathrm{~kg} / \mathrm{m}^{3}$. The fineness modulus of the sand was 2.8 and the water to cement ratio $(w / c)$ was 0.5 . Cylindrical $(150 \times 300$ $\mathrm{mm})$ specimens were made to determine the compressive strength (ASTM C39) of concrete, $f_{c}{ }^{\prime}$ Splitting tests (ASTM C496) on cylindrical specimens were also used to measure the splitting tensile strength of the concrete, $f_{c t}$. The following average values were obtained at 28 days: cylindrical compressive strength of the concrete, $f_{c}{ }^{\prime}=25.1 \mathrm{MPa}$, splitting tensile strength, $f_{c t}=2.5 \mathrm{MPa}$. The Young's modulus (ASTM C469) was measured as $E_{c}=22.3 \mathrm{GPa}$ and the Poisson's ratio (ASTM C469) under uniaxial compression loading was $v_{c}=0.2$.

The tensile strength of the reinforcing steel, $f_{y}$ was $465 \mathrm{MPa}$. Its Young's modulus, $E_{s}$ and passion ratio $\mathrm{v}_{s}$, were $200 \mathrm{GPa}$ and 0.3 , respectively. The properties of the FRP sheets used in this study are shown in Table 1. Mechanical properties of FRP laminates can be measured following the ASTM D-3039 standard guidelines.

A two-component epoxy was used for bonding the FRP sheets to concrete. Its viscosity at room temperature was between $600 \mathrm{cps}$ to $700 \mathrm{cps}$. The

Table 1 Details of FRP strengthened RC beam specimens

\begin{tabular}{cccccccc}
\hline Specimen & FRP & $t_{f}, \mathrm{~mm}$ & $E_{f 1}, \mathrm{GPa}$ & $f_{f u l}, \mathrm{MPa}$ & $E_{f 2}, \mathrm{GPa}$ & $f_{f u z}, \mathrm{MPa}$ & $\alpha$, degree \\
\hline B-I-C & Carbon & 1.00 & 87.3 & 925 & 3.2 & 72.4 & $90^{\circ}$ \\
B-П-CG & Carbon-Glass & 1.00 & 95.8 & 986 & 49.3 & 270.2 & $0^{\circ} / 90^{\circ}$ \\
B-П-CA & Carbon-Aramid & 1.00 & 72.4 & 876 & 61.5 & 290.3 & $0^{\circ} / 90^{\circ}$ \\
B-Ш-GG & Glass-Glass & 0.25 & 19.3 & 309 & 19.3 & 309.0 & $-45^{\circ} /+45^{\circ}$ \\
\hline
\end{tabular}

Note: $E_{f l}=$ tensile modulus of elasticity of FRP in primary direction; $E_{f 2}=$ tensile modulus of elasticity of FRP in transverse direction; $f_{f u l}=$ design ultimate tensile strength of FRP in primary direction; $f_{f u 2}=$ design ultimate tensile strength of FRP in transverse direction; $t_{f=}$ nominal thickness of FRP sheet, $\mathrm{mm} ; \alpha=$ fibers orientations. 
Glass transition temperature, $T_{\mathrm{g}}$ of the epoxy was $82^{\circ} \mathrm{C}$ measured following the ASTM D-4065 guidelines. The minimum tensile strength of the epoxy was $50.0 \mathrm{MPa}$, its ultimate elongation capacity was $5 \%$, and it had a tensile modulus of elasticity of $3.18 \mathrm{GPa}$ measured according to the ASTM D-638 provision.

\subsection{Specimen Preparation}

Five identical size wooden frames were constructed and used to cast the concrete beams using the same ready mix concrete batch. Beams were overdesigned for flexural capacity and transverse steel was used at only one side of the beams to ensure that a shear failure will occur at the other side. In Fig. 1, the load scheme and configuration of the transverse and longitudinal steel are shown. The rectangular cross-section of beams had overall dimensions of $150 \times 250 \mathrm{~mm}$.

The beams were smoothed at their edges to eliminate stress concentration effects and to improve the FRP/concrete bond line properties. The control (not strengthened) RC beam specimen was labeled As-built.
All other beam specimens were retrofitted using parallel FRP schemes on two sides for each beam. Two beams were retrofitted using a hybrid composite scheme of Carbon-Glass and Carbon-Aramid (B-П-CG, B-П-CA). One beam was retrofitted using a unidirectional carbon fibre fabric (B-I-C) with an inclination $\alpha=90$ degrees to ensure interception of diagonal cracks. The last beam was retrofitted using $+45^{\circ} /-45^{\circ}$ glass fibres (B-Ш-GG). Dimensions and typical laminates details for the shear strengthening of all retrofitted RC specimens are shown in Fig. 2.

The concrete surface was prepared and made smooth and even before attaching the fibre-reinforced polymer sheets. Small voids on the surface of the RC beams were filled using ordinary cement grout. Using a two-component resin epoxy, the concrete/FRP bond line achieved adequate mechanical properties. Hence, in the numerical modeling, a perfect bond between the concrete and FRP sheets was assumed. Epoxy was
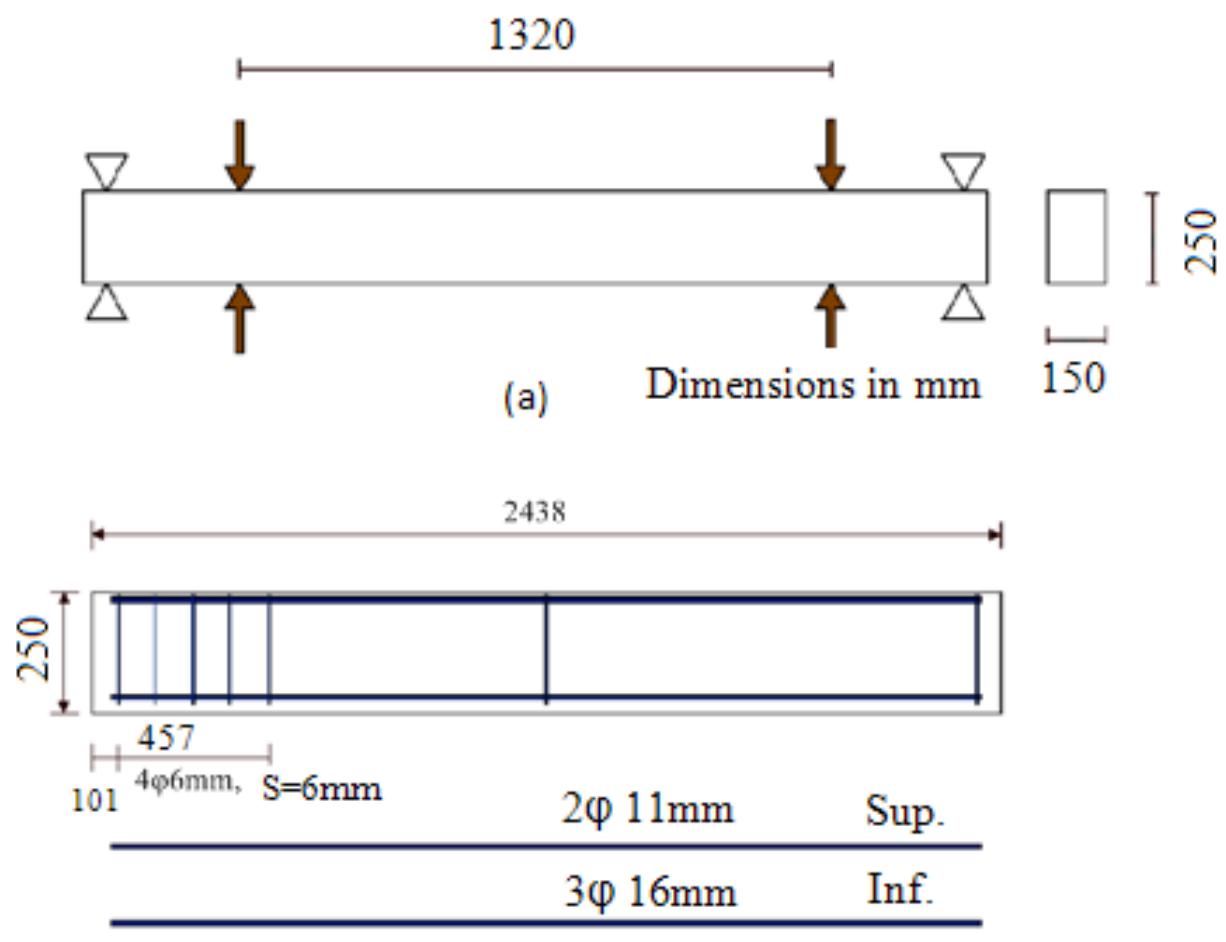

(b)

Fig. 1 Loading scheme and configuration of transverse and longitudinal steel. 


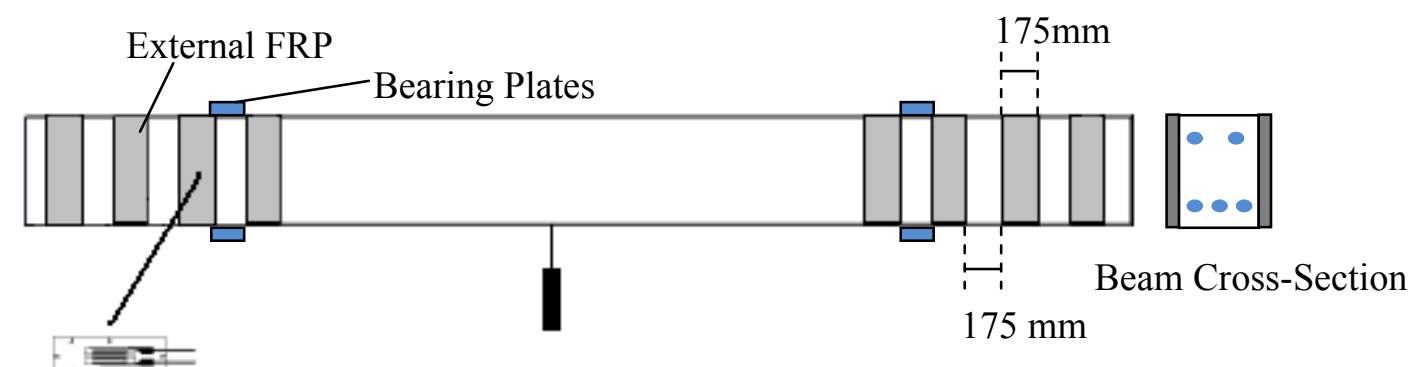

LVDT gauge

Three strain gauges

Fig. 2 Typical shear strengthening details, instrumentation of strain gauges at 0/45/90 degree on FRP sheet and location of LVDT gauge.

combined with the FRP fabrics using the wet-layup method. Approximately 0.8 pounds of epoxy per 1.0 pound of fabric was used.

\subsection{Loading Apparatus and Testing}

The mechanical load was applied using a $250 \mathrm{kN}$ capacity hydraulic jack. The various signals from the instruments were captured and monitored using an automated data acquisition system. Vertical displacements under the applied load were measured using linear variable differential transducers (LVDTs). Strains in the FRP sheets were also measured in three different directions to be able to calculate deformations in the crack zones and to compare the ultimate strain at failure and the effect of transverse fibres on the ultimate strain of the main vertical fibres. In Fig. 2, the instrumentation of the RC beam specimens is illustrated.

To apply quasi-static cyclic loading and to divide the load between two points, a rigid steel beam was utilized on top of the concrete beam. The steel beam was attached to the concrete beam using two steel plates with dimensions of $203 \times 76 \times 38 \mathrm{~mm}$ at the top and bottom of the beams. The steel plates were connected to each other using eight steel rods with a diameter of $12.7 \mathrm{~mm}$. In Fig. 3, the experimental set up and loading cross-section are shown. To prevent the vertical displacement of beams in two directions at the supports, two steel beams were attached vertically on top of the $\mathrm{RC}$ beam and connected to the strong floor. The loading was applied in a deflection control manner. The first cycle of loading had a deflection of $\pm 3 \mathrm{~mm}$ in the actuator, so that the beam experiences both compression and tension. The actuator displacement frequency was set at $0.005 \mathrm{~Hz}$ throughout the test. For every other cycle, the amplitude of the actuator displacement had an increment of $3 \mathrm{~mm}$ both in the tension and compression zone. Each loading cycle was repeated three times to ensure a stable behaviour.

\section{Computational Analysis}

The finite element program ABAQUS ${ }^{\mathrm{TM}}$ [19] was used to model the behaviour of the RC beams under monotonic loading up to failure and to predict their ultimate load capacity. Since the experimental loading was quasi-static, monotonic loading was used to simulate the overall behaviour of the beam.

\subsection{Materials Properties and Constitutive Models}

The materials used in the numerical analysis are concrete, steel and FRP. The constitutive models for the behaviour of these materials are presented below:

\subsubsection{Steel}

The steel rebar is assumed to have an elastic perfectly plastic behaviour as shown in Fig. 4. In ABAQUS $^{\mathrm{TM}}$ [19], the steel reinforcement is treated as an equivalent uniaxial material smeared throughout the element section and can be defined alone or embedded 


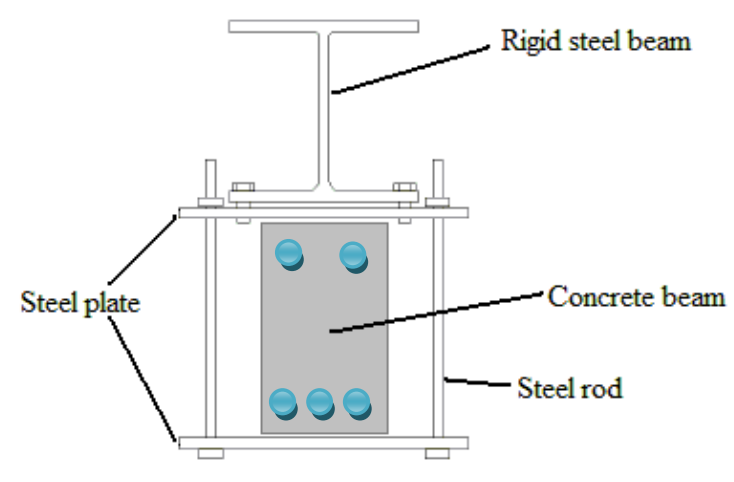

(a)

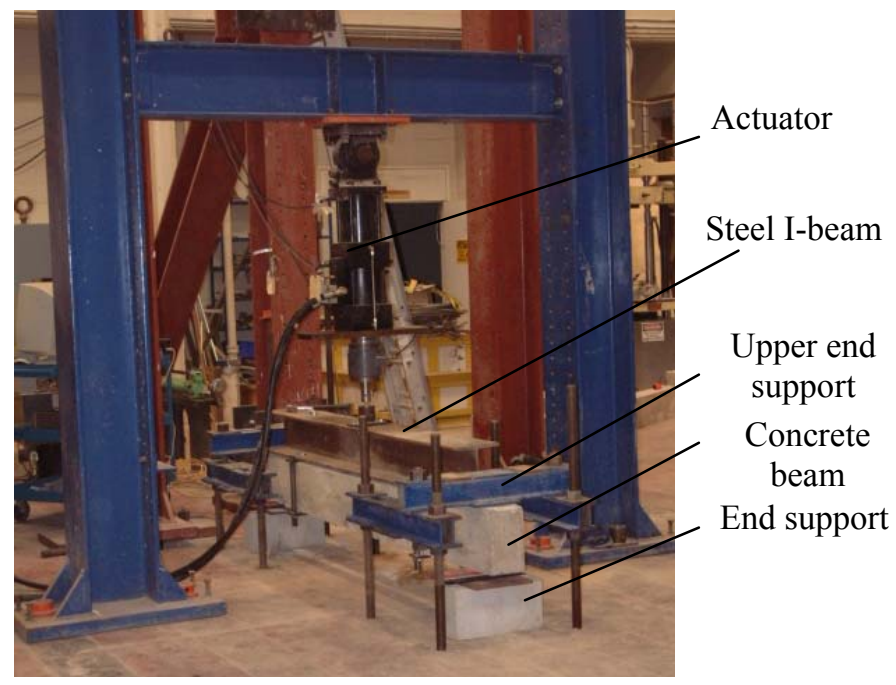

(b)

Fig. 3 (a) Loading cross-section and (b) Experimental set up.

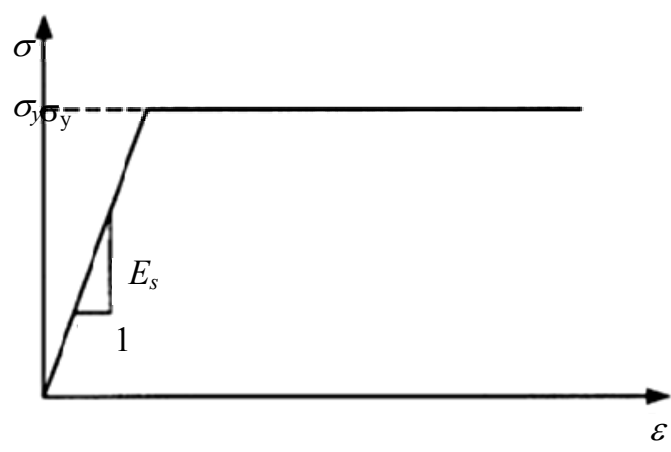

Fig. 4 Stress-strain relationship for steel.

in oriented surfaces. In order to properly model the constitutive behaviour of the steel reinforcement, the cross-sectional area, spacing, position and orientation of each layer of steel bar within each element needs to be specified. In the present model, two surface sections were defined for the top and bottom rebars with one layer of rebar in each surface. Steel ties were defined in surface sections using the same approach. These surfaces were embedded in the concrete section. Material parameters for steel rebars were obtained from experimental data as discussed earlier in sections $3-1$.

\subsubsection{Concrete}

Concrete Damage plasticity was used to model the concrete. It is a continuum, plasticity-based damage model for concrete, which uses concepts of isotropic damage elasticity in combination with isotropic tensile and compressive plasticity to represent the inelastic behaviour of concrete. The model assumes that the main two failure mechanisms are tensile cracking and compressive crushing of the concrete material. Beyond the failure stress, the formation of micro-cracks is represented macroscopically with a softening stress-strain response, which induces strain localization in the concrete structure.

The inputs for the model are the compressive and tensile stresses of the concrete along with damage parameters in terms of plastic strains. The concrete strain, $\varepsilon_{o}$ corresponding to the peak stress, $f_{c}{ }^{\prime}$ is usually in the range of $0.002-0.003$. A representative value suggested by the ACI Committee 318 and used in the analysis is $\varepsilon_{o}=0.003$ [20]. For the compressive behaviour of concrete, the stress-strain relationship proposed by Saenz [21] was used, and the softening branch was assumed to be linearly decreasing from 23 MPa to $2 \mathrm{MPa}$ (from $\varepsilon_{c}=0.003$ to $\varepsilon_{c}=0.01$ ) (Fig. 5).

$$
\sigma_{c}=\frac{E_{c} \varepsilon_{c}}{1+\left(R+R_{E}-2\right)\left(\frac{\varepsilon_{c}}{\varepsilon_{o}}\right)+(2 R-1)\left(\frac{\varepsilon_{c}}{\varepsilon_{o}}\right)^{2}+R\left(\frac{\varepsilon_{c}}{\varepsilon_{o}}\right)^{3}}
$$

Where

$$
R=\frac{R_{E}\left(R_{\sigma}-1\right)}{\left(R_{\varepsilon}-1\right)^{2}}-\frac{1}{R_{\varepsilon}} ; R_{E}=\frac{E_{c}}{E_{o}} ; E_{o}=\frac{f_{c}^{\prime}}{\varepsilon_{o}}
$$


and $R_{\sigma}=4, R_{\varepsilon}=4$.

The tensile strength of concrete is typically $8-15 \%$ of its compressive strength [22]. A value of $2.5 \mathrm{MPa}$ measured from the splitting tensile test was used. The softening part of the tensile stress-strain curve is modeled by two lines as shown in Fig. 5 .

The damage plasticity model in ABAQUS ${ }^{\mathrm{TM}}$ requires the following parameters to be defined: yield and failure surfaces (Table 2). In Table 2, $f_{b o}$ is the biaxial compressive strength, and $f_{c o}$ is the uniaxial compressive strength used to define the yield and failure surfaces. $K$ is the ratio of the second stress invariant on the tensile meridian, to that on the compressive meridian. The model also needs damage evolution in terms of plastic strain; this data was obtained from [23]. Moreover, it was assumed that concrete recovers $95 \%$ of its strength in compression after initial damage.

\subsubsection{FRP}

FRP layers were modeled using membrane elements. FRP was considered to be orthotropic and elastic. Since FRP layers generally behave differently in three orthogonal directions, an orthotropic elastic constitutive model was used. It was also assumed that non-linear behaviour of FRP is negligible. Since no bending was assumed for FRP layers, simple planar membrane elements were used. Bonding between FRP

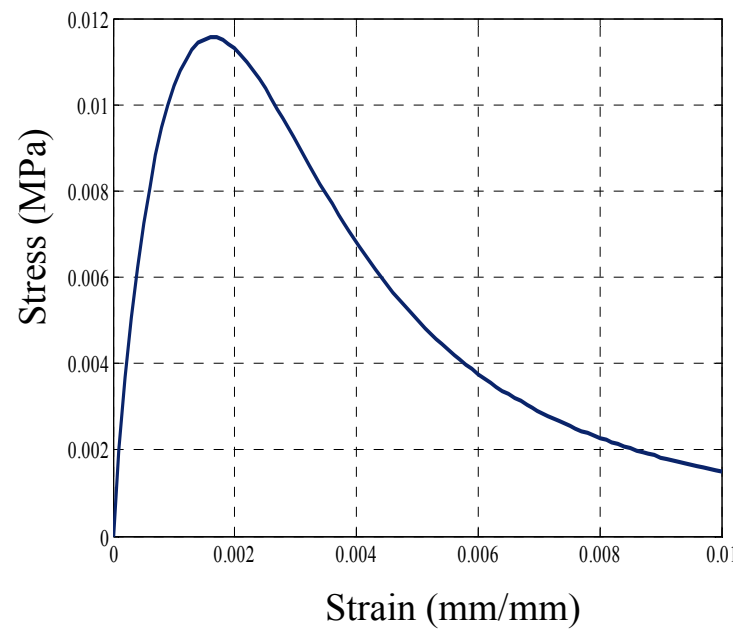

(a) and concrete was modeled by constraining membrane elements to brick elements.

\subsection{FEM Model}

Since the RC beams were not symmetric, they had to be modeled over their entire length. Concrete was modeled using ordinary 8 -noded solid brick elements with $3 \times 4 \times 50$ mesh ties. Steel rebars were modeled using surface elements, while FRPs were modeled by membrane elements. The problem was solved in a displacement control manner. Since modeling was based on monotonic loading, two beams were modeled for each experimental beam, one for downward loading and the other for upward loading.

\section{Results and Discussion}

\subsection{Experimental}

In all tests, no major cracks were observed until near the ultimate load. However, as illustrated in Fig. 6 the effect of stress concentration at the steel plates contact surface with concrete led to separation of some concrete due to the bearing stress before failure occurred. As expected, failure occurred at the side of the beam with no transverse steel. Beams had lower deflection and higher force for the same amount of actuator displacement in downward loading with

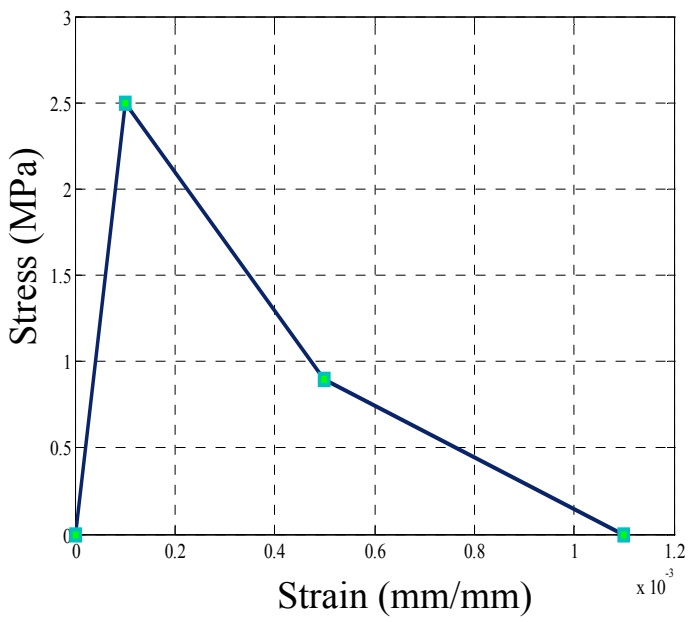

(b)

Fig. 5 (a) Compressive behaviour of concrete used in FEM model, and (b) Tensile behaviour of concrete used in FEM model. 
Table 2 Damage parameters in plasticity model used for concrete.

\begin{tabular}{ccccc}
\hline Dilation angle & Eccentricity & $f_{b o} / f_{c o}$ & $K$ & Viscosity parameter \\
\hline 40 & 10 & 1.16 & 0.667 & 0 \\
\hline
\end{tabular}

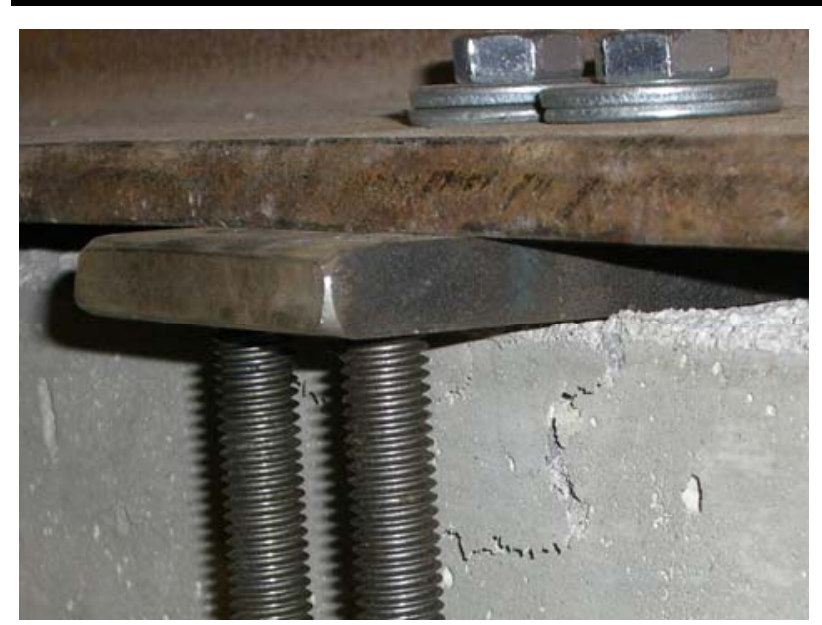

Fig. 6 Bearing stress effect on contact surface of steel and concrete.

respect to upward loading. This shows the importance of the shear span ratio and longitudinal rebar effect on the structural behaviour of concrete beams, because except for the longitudinal steel rebar sizes, the beams were symmetric at the top and bottom. Concrete crashed at the compression zone where no steel ties were used, and longitudinal steel rebars did not yield throughout the experiment. Loading was done using incremental amplitudes of the actuator displacement ( $\pm 3 \mathrm{~mm} ; \pm 6 \mathrm{~mm}$; etc.). Each cycle, except the last one, was repeated thrice to model the effect of repetitive loading. Fig. 7 shows the load-deflection $(P / \delta)$ hysteretic curves at mid span of the beam specimens. The ductility of all specimens was improved slightly after being retrofitted. The maximum compressive and tensile values of strains at different locations, and load versus deflection values were summarized in Table 3 .

The control beam without FRP sheets had an ultimate failure load of $145.7 \mathrm{kN}$. Shear cracks developed suddenly at the maximum shear span at about $45^{\circ}$ inclination, followed by a sudden shear failure in the weak side of the beam specimen as illustrated in Fig. 8a. Failure occurred at the second cycle of the last amplitude of actuator movement $( \pm 12$ $\mathrm{mm}$ ). Some small cracks became visible at the first cycle of the last amplitude, but no major cracks were observed.

Various retrofit protocols consisting of four strips of (1) carbon/epoxy, (2) carbon-glass/epoxy, and (3) carbon-aramid/epoxy hand layup systems, were applied to the treated shear span concrete surfaces of beams designated as B-I-C, В-П-CG and В-П-CA, respectively. Although the main strengthening material, CFRP, is brittle in nature, increasing the ductility of RC beams in which CFRP has been used for strengthening can be achieved. Beam B-I-C failed at the first cycle of the $\pm 15 \mathrm{~mm}$ actuator load, while beams B-П-CG and B-П-CA failed at the actuator load of $\pm 18 \mathrm{~mm}$. Beam B-II-CA achieved the best performance. Its ultimate capacity increased by $35 \%$ compared to the measured value for the control RC beam specimens. The ultimate failure mode of the retrofitted specimens was a typical concrete crushing. Shear cracks initiated at the un-strengthened areas of the shear span. The failure angle changed from 45 degrees for the control beam to 55 degrees, and the third FRP sheet got separated from the RC beam along with a relatively thick concrete layer. Failure was brittle and accompanied by a loud sound. By comparison of the maximum FRP strain values in downward and upward loading of beams retrofitted by hybrid FRP sheets (B-II-CG, B-II-CA) with the observed values for beam B-I-C which had only unidirectional carbon fibres, it can be concluded that the hybrid application of FRP sheets increased the chance of rupture at the main fibres and allowed them to contribute more shear capacity. Fig. $8 \mathrm{~b}$ and Fig. $8 \mathrm{c}$ illustrates the failure of beam specimens B-I-C and B-П-CG.

A repair technique consisting of four strips of glass-glass/epoxy hand layup system was applied to the treated shear span concrete surfaces of the beam designated as B-W-GG. Bidirectional glass fibres in the $-45^{\circ}$ and $+45^{\circ}$ directions were applied for 


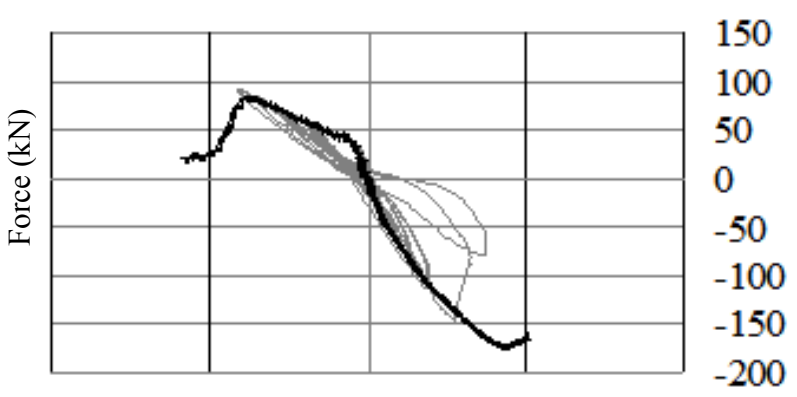

$\begin{array}{lccc}-20 & -10 & 0 & 10 \\ & & \text { Displacement }(\mathrm{mm})\end{array}$

(a)

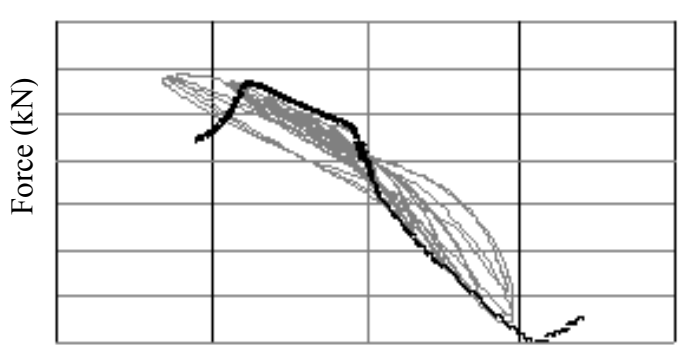

150
100
50
0
-50
-100
-150
-200

$\begin{array}{lllll}-20 & -10 & 0 & 10 & 20\end{array}$

Displacement (mm)

(c)

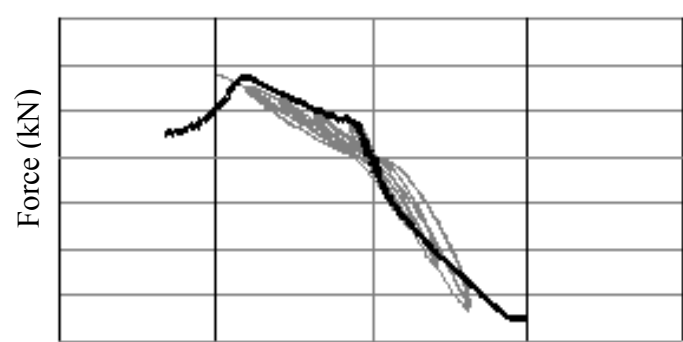

150

100

50

0

$-50$

$-100$

$-150$

$-200$

$\begin{array}{llcr}20 & -10 & 0 & 10\end{array}$

(b)

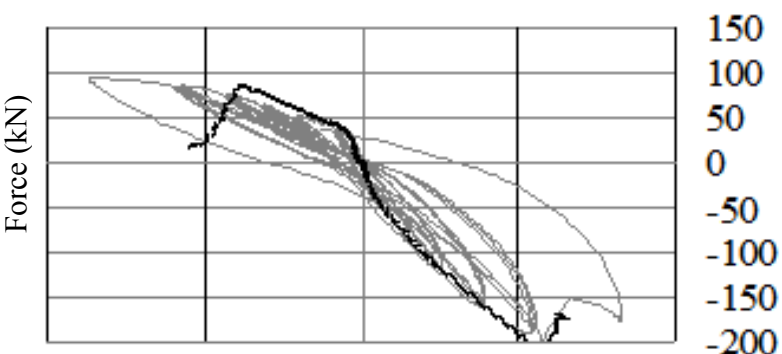

$\begin{array}{lllll}-20 & -10 & 0 & 10 & 20\end{array}$

Displacement (mm)

(d)

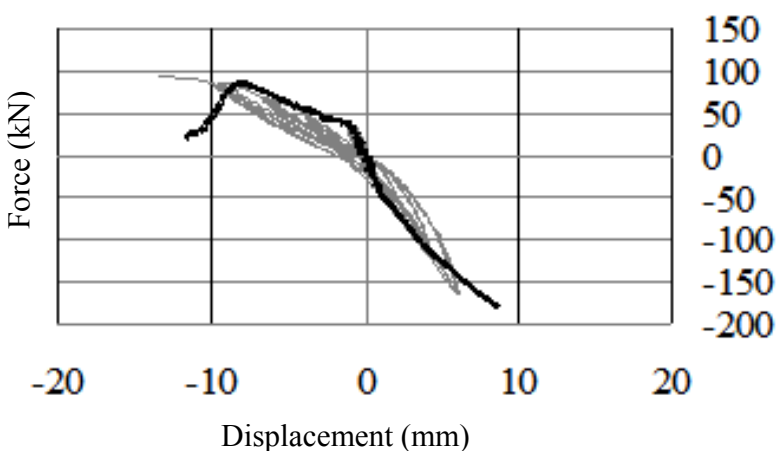

(e)

Fig. 7 FEM prediction and experimental results for the force-displacement behaviour of RC beams: (a) As-built beam, (b) B-I-C, (c) B-II-CG, (d) B-I-CA, and (e) B-II-G. ( Numerical, — Experimental).

Table 3 Experimental results of shear capacity of FRP retrofitted RC beam specimens.

\begin{tabular}{cccccc}
\hline & $\begin{array}{c}\text { Force, } \\
(\mathrm{kN})\end{array}$ & $\begin{array}{c}\text { Displacement, } \\
(\mathrm{mm})\end{array}$ & 7.3 & \multicolumn{3}{c}{ Strain } \\
\cline { 3 - 6 } & 145.7 & 6.9 & - & 45 & - \\
As-Built & 166.2 & 9.6 & 0.003 & 0.010 & 0.009 \\
B - I- C & 178.4 & 11.9 & 0.005 & 0.012 & 0.011 \\
B-П-CG & 196.8 & 6.2 & 0.007 & 0.014 & 0.012 \\
B-П-CA & 163.8 & & 0.010 & 0.017 & 0.013 \\
B-П-GG & & & & & \\
\hline
\end{tabular}


retrofitting this beam. The ultimate capacity of the repaired beam was $163.8 \mathrm{kN}$, which indicates that the glass-glass/epoxy hand layup system ffectively improved the shear strength of the original beam by up to $12 \%$. The failure angle was approximately 45 degrees and the FRP sheet ruptured at the failure. The lower thickness and strength of glass FRP sheets compared to that of the carbon FRP sheets used for the other beams allowed fibres to reach their maximum strain capacity and experience rupture instead of de-bonding. Fig. 8d illustrates the shear failure of the B-III-GG beam specimen.

\subsection{Computational Model}

\subsubsection{As-built Shear Beam Specimens}

The first model predicted cracking load in compression for the original beam was $43.4 \mathrm{kN}$, which is $1 \%$ lower than the corresponding experimental value $(44.0 \mathrm{kN})$. Fig. 7 a shows that in downward loading the post cracking behaviour, i.e., when cracks propagate in the beam and the beam's response becomes non-linear, is well described by the numerical model, since the numerical values form the envelope for the experimental values and the overall error is negligible. The ultimate load was estimated to be $173 \mathrm{kN}$, which is $20 \%$ larger than the observed value. This appears to be due to fatigue loading and the existence of micro-cracks in the original specimen. The cracking pattern in downward loading is illustrated in Fig. 9a which shows that the main cracks are due to shear and appear at 45 degrees in the beam side where there were no ties. Some small flexural cracks were also observed.

\subsubsection{Specimens with CFRP at Main Direction}

(1) Carbon/Epoxy Retrofit Scheme (Specimen B-I-C)

The computational model prediction was in reasonable agreement with experimental data in the elastic range. The cracking load was $36 \mathrm{kN}$, which is $15 \%$ lower than the observed value. The ultimate load was $173 \mathrm{kN}$ and the maximum displacement was 9.5 $\mathrm{mm}$, which are $4 \%$ and $29 \%$ larger than the corresponding experimental values (Fig. 7b). The cracking pattern was changed (Fig. 9b) compared to that of the As-built beam due to the existence of external FRP sheets and a wider area of concrete cracked compared to that of the control $\mathrm{RC}$ beam, which shows that the external FRP increased the beam ductility.

(2) Hybrid Carbon-Glass/Epoxy and Hybrid Carbon-Aramid/Epoxy Retrofit Scheme (Specimens B-II-CG, B-II-CA)

Model predictions for these beams were in a very good agreement with experimental data in the elastic range. The post cracking trend agrees well with experimental observation in the downward and upward loading (Fig. 7c and Fig. 7d)). FRP has changed the cracking pattern in the beams compared to that of control beam. FRP increased the cracking area. Moreover, these beams experienced higher maximum strain compared with that of B-I-C. The maximum strain experienced by FRP sheets to retrofit beams B-II-CG and B-II-CA were $28 \%$ and $37 \%$ higher compared to that of B-I-C at failure. This experimental and computational observation proves that hybrid application of FRP sheets and application of glass or aramid fibres at transverse direction has considerable effect on shear capacity contributed by FRP sheets. Beside shear cracks, some flexural cracks were also observed at the bottom of the beams.

4.2.3 Hybrid Glass-Glass/Epoxy Retrofit Scheme (Specimen B-W-GG)

The computational cracking load for B-III-GG beam specimen was $36 \mathrm{kN}$, which is $16 \%$ below the experimentally measured value. The post-cracking trend was also compatible with experimental data. The computational analysis continued beyond experimental observation, to a computational ultimate load of 198 $\mathrm{kN}$, which is $20 \%$ above the corresponding experimental value. The model predicts the rupture of the third FRP sheet at the weak side of the beam, which is compatible with experimental observation. Stress distributions in FRPs in two sides of the beam with or 
without steel ties are presented in Fig. 10. Internal steel ties had considerable effect in lowering the stress magnitude in FRP attachments.

\subsection{Hybrid FRP Effect}

Debonding of FRP sheets does not allow such sheets to contribute their maximum capacity to the ultimate shear load of RC beams. Generally, the application of most mechanical anchors or bolts to prevent this debonding has not been successful, mainly because of

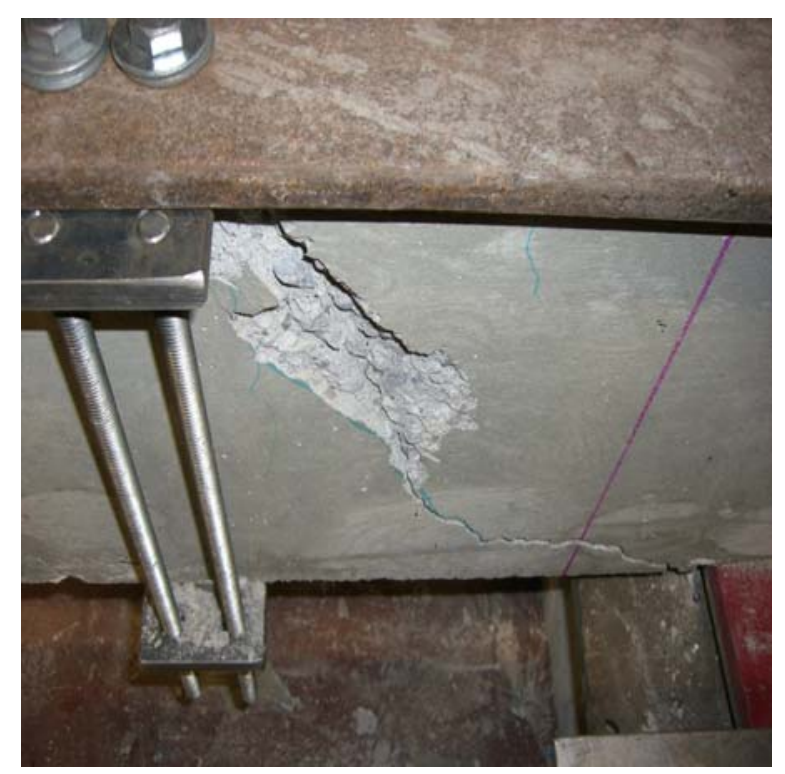

(a)

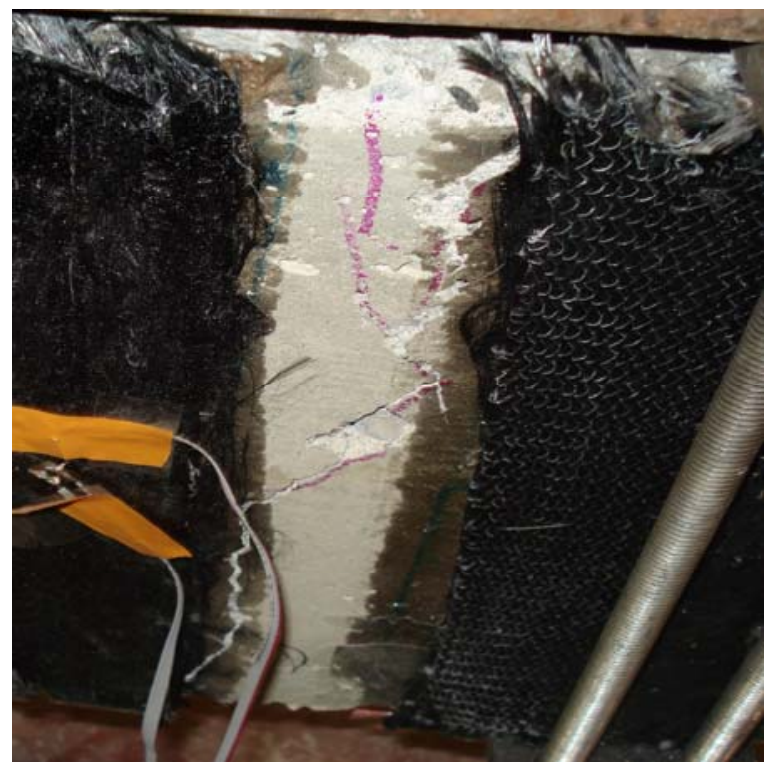

(c) stress concentration effects. The present study shows that the hybrid application of FRP sheets increases the confinement of fibres in the main direction, and consequently the entire FRP laminate shows better stress-strain behaviour and debonding of the FRP sheets can be postponed. Adding a ply in the $0^{\circ}$ or $45^{\circ}$ direction increases the shear friction strength and hindered the crack development at the tension face. Moreover, hybrid application of FRP sheets increases the contribution of the concrete to shear resistance by

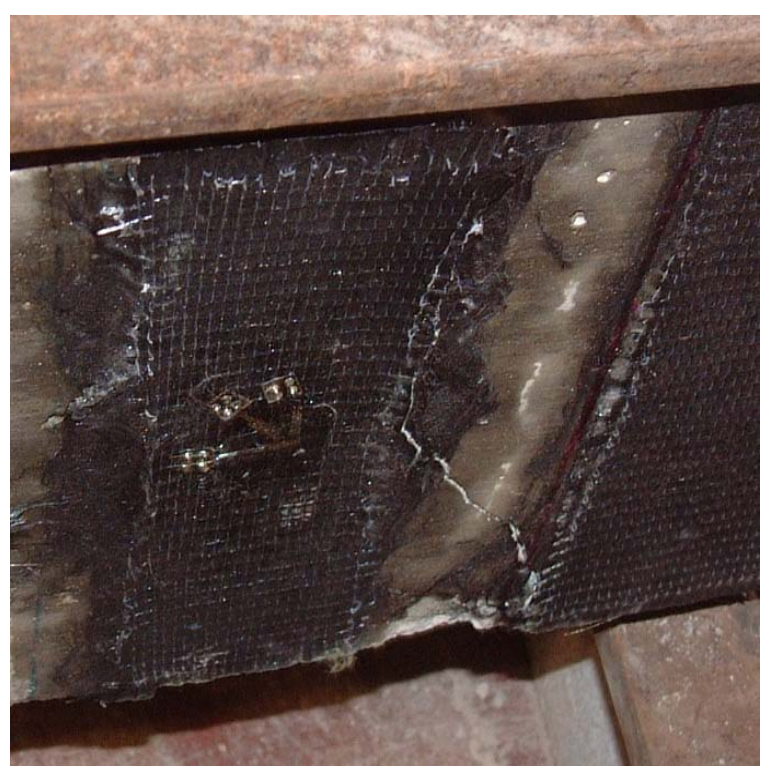

(b)

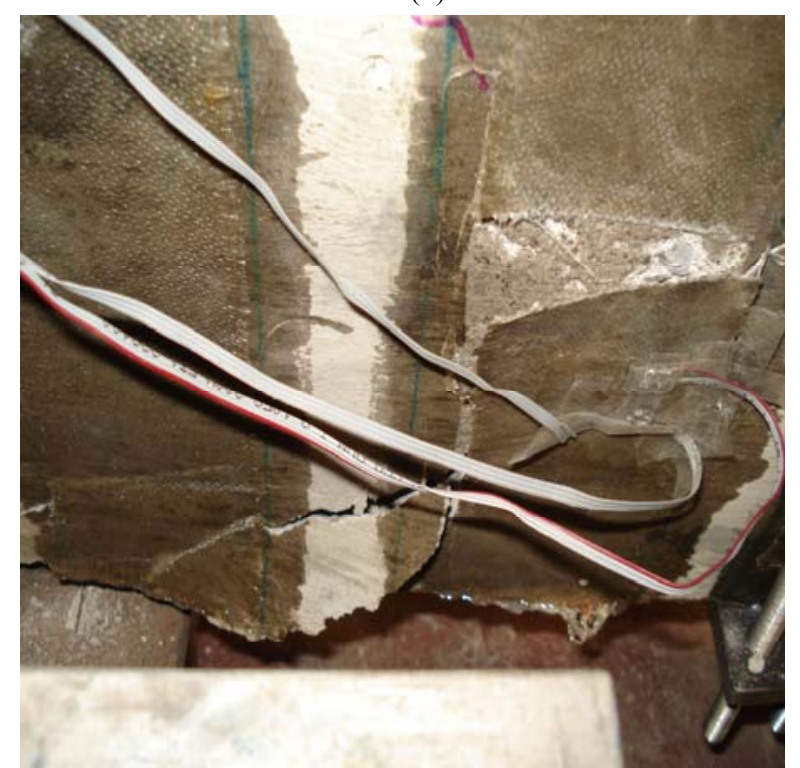

(d)

Fig. 8 Shear failure and crack pattern for: (a) As-built RC specimen (b) B-I-C specimen, (c) B-II-CG specimen, and (d) B-III-GG specimen. 


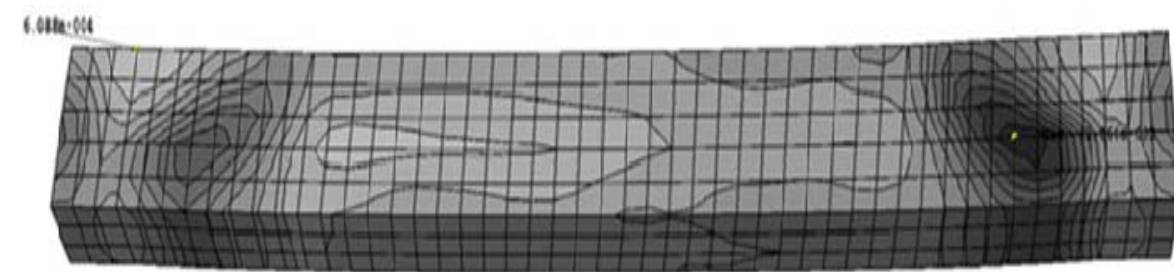

(a)

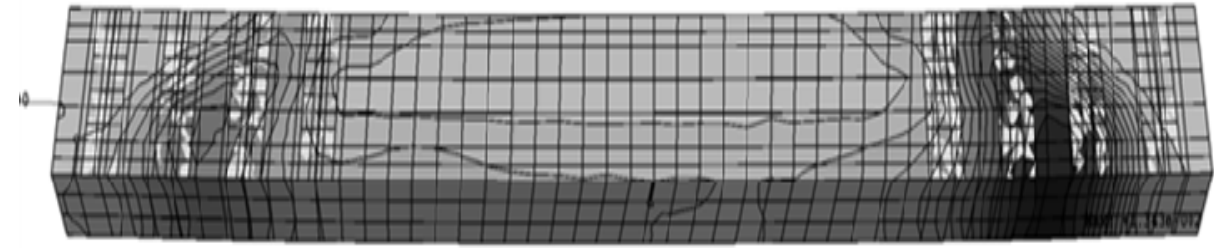

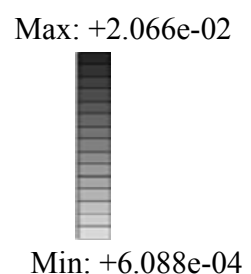

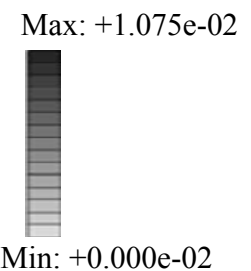

(b)

Fig. 9 FEM results for the maximum principal plastic strain contour for RC beam specimens: (a) As-built beam, (b) B-I-C.
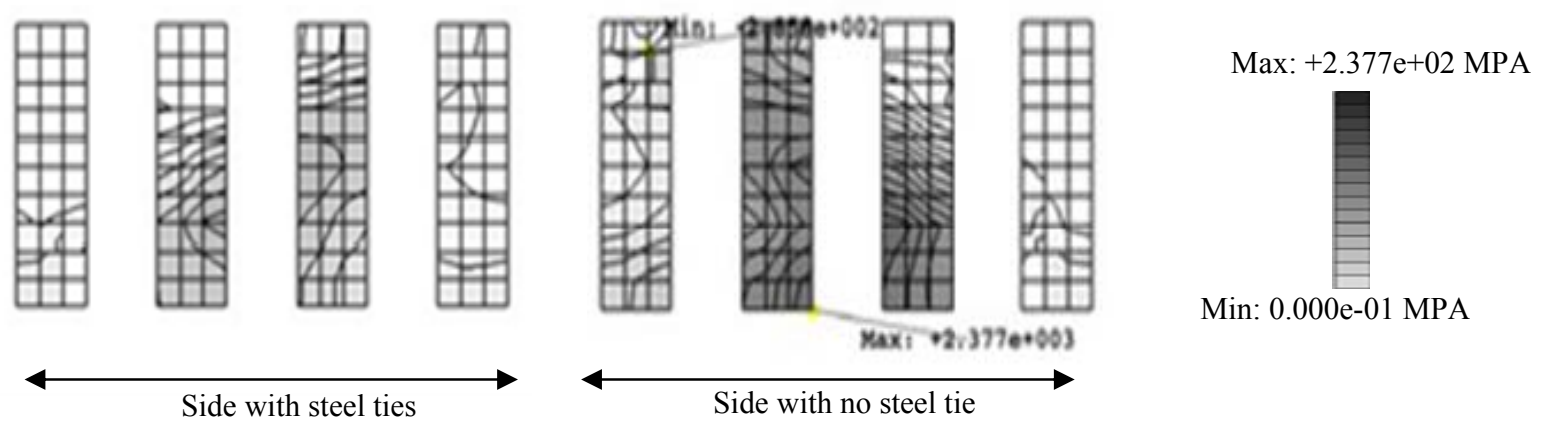

Fig. 10 Stress in the main direction of the FRP sheet at the onset of rupture.

postponing the crack propagation at the concrete surface.

\section{Conclusions}

The objective of the experimental program and computational analysis in the present study was to evaluate the ultimate shear strengths and to identify the modes of failure of a control RC beam, along with that of unidirectional and hybrid FRP retrofitted beam specimens under quasi-static cyclic loading. The following conclusions can be drawn based on the experimental and computational research discussed in this paper:

(1) Hybrid FRP sheets showed a better performance in increasing the ultimate shear capacity of RC beams compared with that of unidirectional fibre-retrofitted beam specimens. The co-existence of other fibres like glass or aramid in the transverse direction allowed fibres in the main direction to get closer to their ultimate strain capacity.

(2) Different structural behaviour of RC beams in upward and downward loading confirmed the importance of shear span to depth ratio, $a / d$, and the longitudinal rebar effect on the shear behaviour of RC beams.

(3) Repetitive loading affect the ultimate capacity of $\mathrm{RC}$ beams through the formation of micro-cracks in concrete and weakening of the bonding layer between concrete and the external FRP sheets.

(4) Finite element method proved to be an effective technique for modelling $\mathrm{RC}$ beams with unidirectional or hybrid external FRP attachments. 


\section{Acknowledgments}

Continued financial support to $M$. Nehdi by the Natural Science and Engineering Research Council of Canada (NSERC) has been necessary for this research and is acknowledged. The authors also gratefully acknowledge the support given to this project by the Fibrewrap Company, San Diego, CA, USA, by providing FRP sheets.

\section{References}

[1] A. Khalifa and A. Nanni, Improving shear capacity of existing RC T-section beams using CFRP composites, Cem. Concr. Compos. 22 (3) (2000) 165-174.

[2] V. Colotti, G. Spadea and N. Swamy, Analytical model to evaluate failure behaviour of plated reinforced concrete beams strengthened for shear, ACI Struct. J. 101 (6) (2005) 755-765.

[3] C. Pellegrino and C. Modena, Fibre-reinforced polymer shear strengthening of reinforced concrete beams: experimental study and analytical modeling, ACI Struct. J. 103 (5) (2006) 720-728.

[4] A. Mosallam and S. Banerjee, Shear enhancement of reinforced concrete beams strengthened with FRP composite laminate, Composites Part B 38 (5-6) (2007) 781-793.

[5] M. Nehdi and H. Nikopour, Genetic algorithm model for shear capacity of RC beams reinforced with externally bonded FRP, J. Mater. Struct., 44 (7) (2011) 1249-1258.

[6] H. Nikopour and M. Nehdi, Shear repair of concrete beams using external FRP sheets and epoxy injection methods, J. Mater. Struct., 44 (10) (2011) 1865-1877.

[7] S. Kim and R. S. Aboutaha, Finite element analysis of carbon fiber-reinforced-polymer (CFRP) strengthened reinforced concrete beams, Comput. Concr. 1(4) (2004) 401-416.

[8] H. J. Lin, C. I. Liao and C. Yang, A numerical analysis of compressive strength of rectangular concrete columns confined by FRP, Comput. Concr. 3 (4) (2006) 235-248.

[9] M. Hoque, N. Rattanawangcharoen, A. H. Shah and Y. M. Desai, 3D nonlinear mixed finite-element analysis of RC beams and plates with and without FRP reinforcement, Comput. Concr. 4 (2) (2007) 135-156.

[10] J. G. Park, K. M. Lee, H. M. Shin and Y. J. Park, Nonlinear analysis of RC beams strengthened by externally bonded plates, Comput. Concr. 4 (2) (2007) 119-134.
[11] C. G. Cho, H. C. Yun and Y. Y. Kim, Displacement-based seismic design of reinforced concrete columns strengthened by FRP jackets using a nonlinear flexural model, Comput. Concr. 6 (2) (2009) 95-108.

[12] A. B. Dogan and O. Anil, Nonlinear finite element analysis of effective CFRP bonding length and strain distribution along concrete-CFRP interface, Comput. Concr. 7 (5) (2010) 437-453.

[13] R. A. Hawileh, J. A. Abdalla, M. H. Tanarslan and M. Z. Naser, Modeling of nonlinear cyclic response of shear-deficient RC T-beams strengthened with side bonded CFRP fabric strips, Comput. Concr. 8 (2) (2011) 193-206.

[14] G. Wu, Z. S. Wu, Z. T. Lu and Y. B. Ando, Structural performance of concrete confined with hybrid FRP composites, Reinf. Plast. Compos. 27 (12) (2008) 1323-1348.

[15] A. P. S. Selvadurai and H. Nikopour, Transverse elasticity of a uni-directionally reinforced composite with an irregular fibre arrangement: Experiments, theory and computations, Compo. Struct. 94 (6) (2012) 1973-1981.

[16] J. Li, B. Samali, L. Ye and S. Bakoss, Behaviour of concrete beam-column connections reinforced with hybrid FRP sheet, Compos. Struct. 57 (1-4) (2002) 357-365.

[17] J. Li, Y. C. Guo, F. Liu and J. H. Bungey, Efficiency of hybrid FRP sheets in strengthening concrete beams, in: Proceedings of the International Conference on Repair and Renovation of Concrete Structures, Dundee, UK, 2005.

[18] G. Sakar, H. M. Tanarslan and O. Z. Alku, An experimental study on shear strengthening of $\mathrm{RC}$ T-section beams with CFRP plates subjected to cyclic load, Mag. Concr. Res. 61 (1) (2009) 43-55.

[19] ABAQUS 6.6 User's Manual, ABAQUS Inc., Providence, RI, USA, 2006.

[20] ACI Committee 318, Building Code Requirements for Structural Concrete (ACI 318-05) and Commentary (318R-05), American Concrete Institute, Farmington Hills, Michigan, USA, 2005.

[21] L. P. Saenz, Discussion of "Equation for the stress-strain curve of concrete" by Desayi P., Krishnan S., ACI Struct. J. 61 (3) (1964) 1229-1235.

[22] S. P. Shah, S. E. Swartz and C. Ouyang, Fracture Mechanics of Concrete, John Wiley \& Sons, Inc., New York, USA, 1995.

[23] T. Jankowiak and T. Lodygowski, Identification of Parameters of Concrete Damage Plasticity Constitutive Model, Publishing House of Poznan University of Technology, Poznan, Poland, 2005. 